\title{
Medición de la actividad respiratoria por volumetría para detectar diferencias en un suelo tratado con distintas enmiendas orgánicas.
}

Martin* ${ }^{1}$, Luisa C. Cossoli ${ }^{1}$, Marcela R.;Romero ${ }^{1}$, Amalia M. E.; Alconada M $^{2}$, Margarita M.

${ }^{1}$ Cát. de Microbiología Agrícola. FCA - UNNE. Sargento Cabral 2131 - Corrientes.

Tel. /fax:+54(379) 4427589 int. 158

${ }^{2}$ Cát. de Edafología, FCAyF, UNLP. Calle 60 y 119. La Plata. Buenos Aires. +54 (221) 4236616

E-mail: 1.ceciliamartin@gmail.com

Introducción:Se busca revertir la degradación edáfica por pérdida de materia orgánica, salinización y alcalinización, y asociado a esto, desbalances nutritivos y desarrollo de enfermedades. Grandes volúmenes de estiércol de pollo en cama de arroz fresca es agregada anualmente como enmienda orgánica al suelo dedicado a un uso hortícola intensivo. Sin embargo, su calidad ni efectividad ha sido debidamente probada. Mediante el proceso de compostaje se reduce la población microbiana patógena, por las altas temperaturas que se generan en dicho proceso. El desprendimiento de $\mathrm{CO}_{2}$, en un tiempo determinado (respiración) es uno de los parámetros más frecuentemente usado para cuantificar la actividad microbiana en el suelo y permitiría inferir el efecto de las enmiendas orgánicas aplicadas al suelo en diferentes dosis. El objetivo de este trabajo fue medir a través de la actividad respiratoria, el efecto de la incorporación de diferentes enmiendas orgánicas frescas y compostadas a un suelo degradado por uso intensivo hortícola.

Materiales y métodos: Se trabajó en un suelo Hapludert típico de la Chacra Experimental de Gorina (Ministerio de Asuntos Agrarios, partido de La Plata) bajo cobertura plástica, con cultivos de lechuga (Lactuca sativa) y tomate (Solanum lycopersicum). Se realizaron 4 tratamientos: T1: testigo sin enmiendas; T2:cama de pollo fresca (30-40 tn.ha ${ }^{-1}$, dosis de uso frecuente); T3: compost de cama de pollo (dosis equivalente al T2, ajustada por contenido de materia orgánica); T4: agregado de compost de cama de pollo (doble dosis de T3). Diseño experimental bloques al azar con 4 repeticiones (invernáculo $280 \mathrm{~m}^{2}$ ). Se efectuaron cuatro muestreos, el $1^{\frac{\text { er }}{}}$ Muestreo y $2^{\frac{\text { do }}{}}$ Muestreo (inicio y fin en lechuga), el $3^{\text {ro }}$ Muestreo y el $4^{\text {to }}$ Muestreo (inicio y fin en tomate) en cada tratamiento se tomaron muestras compuestas por 6 submuestras, a dos profundidades $(0-10 \mathrm{~cm}$ y $10-20 \mathrm{~cm})$. La actividad respiratoria se mide sobre muestras de suelos molidas y tamizadas por $2 \mathrm{~mm}$, y humedecidas hasta capacidad de campo, incubación

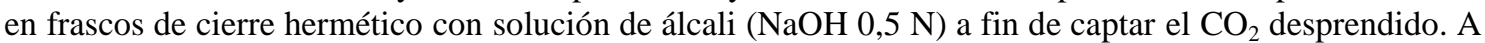
los siete días por retrovaloración, se obtuvieron los $\mathrm{mg} \mathrm{CO}_{2} \cdot 100 \mathrm{~g}^{-1}$.día ${ }^{-1}$. Los datos fueron tabulados y analizados en el programa INFOSTAT, mediante ANAVA, y posterior prueba de Tukey $(p \leq 0.05)$.

Resultados: En la primer profundidad de muestreo $(0-10 \mathrm{~cm})$ hubo diferencias significativas entre tratamientos en las diferentes fechas de muestreo.En el $1^{\text {er }}$ Muestreo el T2 se diferencia significativamente del resto de los tratamientos y es consistente con una mayor actividad microbiana atribuible a la enmienda orgánica fresca. Por el contrario, la enmienda compostada no incrementó la actividad biológica ni respecto al testigo en ninguna de las dos dosis ensayadas, demostrando la efectividad del procedimiento de compostaje. En el $2^{\text {do }}$ Muestreo el T2 continúa con una significativamente mayor actividad biológica pero solo respecto al testigo. En el $3^{\text {er }}$ Muestreo no hubo diferenciación entre los tratamientos y supone una estabilización de los materiales agregados sin compostar en el suelo. Sin embargo, en el $4^{\text {to }}$ Muestreo aumenta nuevamente la actividad biológica y resulta similar al $2^{\text {do }}$ Muestreo, aunque con mayor intensidad. Esto puede ser atribuido a las mayores temperaturas en el invernáculo en el $3^{\text {er }}$ muestreo (verano) respecto al $1^{\mathrm{er}}$ y $2^{\text {do }}$ muestreo (otoño/invierno). En la segunda profundidad de muestreo (10-20 $\mathrm{cm})$ no hubo diferencias significativas y puede ser asociado a la naturaleza vértica de los suelos. Estos presentan alta proporción de arcillas desde superficie $(>30 \%)$ siendo alta la proporción de tipo expansiva, que se incrementa a partir de $\operatorname{los} 10 \mathrm{~cm}$ (> 50\% horizonte $\mathrm{Bt}$ ) por lo cual se dificulta la incorporación de enmiendas, laboreos, permeabilidad, y restringe el desarrollo radicular.

Conclusiones: La actividad biológica de los suelos en superficie varía en función del tratamiento implementado y la fecha de muestreo. A partir de los $10 \mathrm{~cm}$ de profundidad el contenido de arcillas del suelo evita que se diferencien los tratamientos. Los materiales orgánicos compostados disminuyen los riesgos de contaminación y podrían promover la calidad y salud edáfica. Estudios futuros deberían establecer el efecto que estas enmiendas tienen sobre las propiedades edáficas que se intenta revertir mediante su agregado en sistemas intensivos hortícolas.

Agradecimientos:Incentivos UNLP código A302 (M Marasas, M Alconada, L Larrieu,L Juan). Edafología, FCsAg Fs, UNLP (J Lanfranco, A Pellegrini, M Falcone, L Calandrelli, S Ungaro, L Aguirre, F Alegre, N Vescoso). INTA PNHFA 1106082 (M Cuellas). EEGorina (J Luna, N Mezquiris). 